\title{
Increasing Early Awareness of Hazard of Children with ADHD's ODD and Aggression by Structural Equation Modeling (SEM)
}

\author{
Ruu-Fen Tzang ${ }^{1,4,5,}{ }^{*}$, Chuan-Hsin Chang ${ }^{2}$ and Yue-Cune Chang ${ }^{3}$ \\ ${ }^{1}$ Department of Psychiatry, Mackay Memorial Hospital, Taipei, Taiwan \\ ${ }^{2}$ Department of Pharmaceutical Sciences, SkAGGs School of Pharmacy and Pharmaceutical Sciences, \\ Anschutz Medical Campus, University of Colorado, Aurora, CO 80045, USA \\ ${ }^{3}$ Department of Mathematics, Tamkang University, Taipei, Taiwan \\ ${ }^{4}$ Mackay Junior College of Medicine, Nursing, and Management, Taipei, Taiwan \\ ${ }^{5}$ Department of Health Care Management, National Taipei University of Nursing and Health Sciences, Taipei, \\ Taiwan
}

\begin{abstract}
Background: The hazard of children with Attention Deficit Hyperactivity Disorder (ADHD) occurring Oppositional Defiant Disorder (ODD) (shorten as ADHD's ODD) and aggression is not well understood. This study employs structural equation modeling (SEM) to operationalize aggression as joined symptoms on children with ADHD's
\end{abstract} ODD by analyzing how aggression symptom transact the symptom severity of ADHD's ODD.

Methods: ADHD children and adolescents received clinical diagnosis and inattention (ADHD-I), hyperactivity/impulsivity (ADHD-H/l), and ODD subscale of Swanson, Nolan, and Pelham, version IV scale (SNAP-IV-C) and child behaviour check list (CBCL). SEM was applied to associate ADHD-I, ADHD-H/I, and ODD subscale to aggression.

Results: Significantly aggressive symptom on CBCL interact with symptom of ADHD, ODD on SNAP; the standardized direct effect of ADHD symptom by SNAP on behavior symptom by CBCL is 0.57 and the standardized total (direct and indirect) effect of ODD symptom on behavior symptom is 0.34 . Children with ADHD's ODD symptom share similar characteristic symptom as symptom of ADHD children with deficient emotional self-regulation (DESR). The aggression is highly correlated with ODD (0.607).

Conclusions: On ADHD symptom, the likelihood of symptom severity is predicted by the symptom of ADHD-I, ADHD$\mathrm{H} / \mathrm{l}$, and ODD. On ODD symptom, ODD is associated with aggression and anxiety/depression symptom. There is a need to regard child with symptom of ADHD's ODD and aggression as a child with heavy genetic loading and predictor of disruptive behavior disorder.

Keywords: ADHD, ODD, Aggression, DESR, SEM.

\section{INTRODUCTION}

Children with Attention Deficit Hyperactivity Disorder (ADHD) are commonly seen and their problematic behavior is usually not a short-period problem but rather staying in a chronic situation when they also coexist with Oppositional Defiant Disorder (ODD) symptom. Childhood Aggression (AGG) is also a commonly seen even as a normal behavior on developmental process because sometimes kid needs to get attention by AGG (Bowie, 2007). But abnormal Childhood Aggression (AGG) after the child's age of 6 years is disruptive behavior [1]. Such abnormal aggression among child and adolescent is associated to anger/negative emotionality, ADHD [2] or ODD [3].

The association regarding $A G G$ and children with ADHD is simultaneous occurrence of deficient

*Address correspondence to this author at the Department of Psychiatry, Mackay Memorial Hospital, Number 92, Sec. 2, Zhong Shan N Road, Taipei 104, Taiwan; Tel: 886-2-25433535; Fax: 886-2-28098249;

E-mail: rf.tzang@msa.hinet.net emotional self-regulation (DESR) on ADHD children self as prior research found [4]. DESR seen in children with ADHD is characterized with low frustration tolerance, impatience, quickness to anger, and being easily excited to emotional reactions [5]. DESR from literature is a diagnosis of ODD clinically. Longitudinal follow up research found ODD diagnosis play a role to amplify aggression symptom on children with ADHD [6]. Reversely, criminal aggression in later can be predicted by hurtful symptom among children with ODD in their earlier life [7] while symptoms of ODD divided into 3 dimensions: irritable mood, strong head, and hurtful dimension [8]. In summary, aggression is transacting with ODD need a considered cross sectional latent relationship analysis to explore their complexity of transactions.

Accordingly, recent study concerns underlying factors for pathologic developmental converges on children with ADHD and ODD (shortened as ADHD's ODD) by longitudinal follow up study [9]. Because children with both diagnosis of ADHD and ODD had considerable impact on their severe symptom even can 
be considered as a distinct heterogeneous group [10] requiring specific prognostic and treatment implications [11]. Clinically, ODD is really the most regularly seen; high prevalence ranged from $3.87 \%$ [12] to $10 \%$ [13] and difficult disruptive behavior disorders among general pediatric practice [14]. Moreover, the substantial impact of ODD on ADHD is ODD increase the symptom severity of children with ADHD [15] when ODD is co-occurring with ADHD ranged from $40.6 \%$ to $60 \%[16,17]$. Prior developmental trend study found ODD is key pathologic risk for children to develop as depression or conduct disorder because ODD had strong emotional dimensional symptom [18] and Stop Now And Plan (SNAP) Program is devised for boys at risk for violence and delinquency [19].

If we take aggression as an external expression of inappropriate parenting discipline [3] and take child with both ADHD and ODD as biologic risk factors, call for a better understanding of its environmental parenting and biologic association is essentially needed. It is lack of study to explore the latent ongoing processes underlying how external aggression behavior among school aged child and adolescent can influence the symptom severity of ADHD's ODD.

Traditional regression or correlation modeling already link $A G G$ to ODD but may not be very satisfying in exploring how Aggression in CBCL associated with ADHD and ODD in SNAP. Structural equation modeling (SEM) is one of the most appropriate statistical methods to analyze a set of interactive factors simultaneously [20]. Therefore, we build SEM model in which symptoms measured by SNAP are predictor of all the symptoms measured by $\mathrm{CBCL}$ and especially to Aggression. Also we can measure the latent association between ADHD, ODD measure in SNAP and Aggression measure in CBCL by analysis by SEM under the hypothesis children with AGG symptom is associated with symptom of ADHD's ODD. Such study might help clinician to recognize an interactive pathway among AGG and ADHD's ODD earlier instead of waiting for result of CBCL-DESR. Such revealing the latent association between $A G G$ and ADHD' ODD study might remind clinician keep high alert on their symptom severity quickly and to device more parental program and more effective parenting program toward children with ADHD's ODD.

\section{METHODS}

\section{Participants and Data Collection}

Patients were recruited from the Outpatient Units of Mackay memorial hospital which is a major medical center in Taiwan. The research protocol was approved by the Institutional Review Boards (IRB) of the institute. After complete description of the study to the subjects, written informed consent was obtained in line with the IRB's guidelines. 231children were enrolled into this study if they had clinical diagnoses of a Diagnostic and Statistical Manual of Mental Health Disorders, Fourth Edition (DSM-IV) of ADHD. The clinical diagnosis of ADHD was confirmed by experienced child and adolescent psychiatrist by DSM-IV criteria.

\section{Measurements}

\section{Symptoms of ADHD and ODD}

The primary outcome measures were inattention subscale (ADHD-In), hyperactivity/impulsivity subscale (ADHD-H/I), and oppositional defiant disorder (ODD) subscale of Swanson, Nolan, and Pelham, version IV scale (SNAP-IV-C) [21]. These items reflect the core symptoms of ADHD (18 items) and ODD (8 items) as defined in DSM-IV. Each item is scored for severity on a 4-point scale (0-3, where $0=$ not at all; $1=$ just a little; 2 = quite a bit; $3=$ very much). The intraclass correlation coefficients for the three subscales of the Chinese SNAP-IV range from 0.59 to 0.72 for the parent form and from 0.60 to 0.84 for the teacher form. All subscales of both the parent and teacher forms show excellent internal consistency with Cronbach's a greater than 0.88 [22].

\section{Aggressive Behaviour}

The child behaviour check list $(\mathrm{CBCL})$ is designed to obtain competencies and behaviour problems of children aged 4-18 years. The questionnaires, completed by the parents, contain 118 items to assess specific behavioural and emotional problems. The CBCL was translated into Chinese via a two-stage translation [23]. The internal consistency and 1-month test-retest reliability (all $\alpha$ values and reliabilities $>0.6$, except for thought problems) of this Chinese version is satisfactory for Taiwanese patients [24]. In the interest of parsimony, the present study only analysed the following 8 scales: Aggressive Behaviours, Attention Problems, Anxiety/Depression, Social Problems, Delinquent Behaviours, Somatic Complaints, Other problem, and Withdrawal.

\section{Statistical Analyses}

Because this study aims to find how inattentive and hyperactivity/impulsivity symptom of ADHD and ODD interact with Aggression. The SEM method [25] was used to explore the potential direct effect of ADHD 
(Inattention and Hyperactivity), ADHD and ODD interact with Aggression. Factor loadings were used to specify the association between an unobservable construct (latent variable) and its theoretically related measures (indicator variables). Multiple linear regression methods were used to determine the relationships among the aforementioned latent variables and were indexed by standardized path coefficients.

To demonstrate how a proposed SEM fits the sample data, we used the following six indices simultaneously: (1) the chi-square test, $x^{2}$; (2) the comparative fit index, CFI; (3) the Bentler-Bonett [26] normed fit index, NFI; (4) the goodness of fit index, GFI; (5) the Tucker-Lewis index, TLI, which is also known as the Bentler-Bonett non-normed fit index (NNFI); (6) the root mean square error of approximation, RMSEA [27]. A non-significant $x^{2}(p>$ $0.05), \mathrm{GFI}$ and CFI greater than 0.95 , TLI greater than 0.96 , and RMSEA less than 0.06 each indicates a good fitted model between the data and the hypothesized model [28].

\section{RESULTS}

The demographic characteristics of the collected 231 ADHD subjects were shown in Table 1 . The average age was $10.17 \pm 2.59$. There were 158 ADHD patients with a combined subtype (68.7\%). The comorbidity rate was $73.0 \%$.
To explore how inattentive and hyperactivity/ impulsivity symptom of ADHD and ODD interact with Aggression, the SEM method was used. Due to the requirement of non-missing data in SEM, we excluded 48 subjects with incomplete data in CBCL measurements. The zero-order correlations of the indicator variables are displayed in Table 2.

The one-factor confirmatory factor analysis (CFA) of SNAP and CBCL were shown in Figure $\mathbf{1 a}$ and $\mathbf{b}$, respectively. In Figure 1a, the standardized direct effect of SNAP on inattention (ADHD-In), hyperactivity (ADHD-H/I), and ODD were 0.60, 0.84, and 0.69, respectively. More specifically, for example, inattention goes up by 0.60 standard deviations (SD) for each 1 SD goes up in SNAP. This model provided a good fit for the data, as suggested by the non-significant chisquare and good indices of fit $\left(x^{2}(1)=0.199, p=0.656\right.$, $\mathrm{CFI}=1.00, \quad \mathrm{NFI}=0.999, \quad \mathrm{GFI}=0.999, \quad \mathrm{TLI}=1.00$, RMSEA $<0.001$ ). In Figure $\mathbf{1 b}$, the standardized direct effect of CBCL on AGG, anxiety/depression (AnDe), attention problems (AttPr), delinquent behaviours (DestB), social problems (SocP), somatic complaints (Somat), other problem (Thopro), and withdrawal (Withdral) were 0.64, 0.67, 0.88, 0.62, 0.82, 0.40, 0.55, and 0.55 , respectively. This model provided a good fit for the data, as suggested by the non-significant chisquare and good indices of fit $\left(X^{2}(13)=11.062\right.$, $\mathrm{p}=0.606, \mathrm{CFI}=1.00, \mathrm{NFI}=0.984, \mathrm{GFI}=0.985, \mathrm{TLI}=1.00$, RMSEA<0.001).

Table 1: Sample Characteristics and Means and Standard Deviations of Study Measures

\begin{tabular}{|l|c|c|}
\hline Characteristics & N & Mean, \% \\
\hline \hline Age & 231 & 10.17 \\
\hline Male (\%) & 175 & $75.8 \%$ \\
\hline $\begin{array}{l}\text { Comorbidity } \\
\text { Yes }\end{array}$ & 168 & $73.0 \%$ \\
\hline No & 62 & $27.0 \%$ \\
\hline Subtype Combined & 158 & $68.7 \%$ \\
\hline Inattentive & 72 & $31.3 \%$ \\
\hline Education Elementary School & 171 & $75.0 \%$ \\
\hline Junior High School & 54 & $23.7 \%$ \\
\hline Senior High School & 3 & $1.3 \%$ \\
\hline ADHD & 231 & 17.19 \\
\hline Inattention & 231 & 12.43 \\
\hline Hyperactivity & 231 & 12.25 \\
\hline Oppositional Defiant Disorder & 231 & 13.32 \\
\hline Aggression & & 5.46 \\
\hline
\end{tabular}


Table 2: Zero-Order Correlations Among Study Measures

\begin{tabular}{|c|c|c|c|c|c|c|c|c|c|c|}
\hline & 1 & 2 & 3 & 4 & 5 & 6 & 7 & 8 & 9 & 10 \\
\hline 1. Inattention & - & & & & & & & & & \\
\hline 2. Hyperactivity/Impulsivity & $0.506^{* *}$ & & & & & & & & & \\
\hline 3. ODD & $0.435^{\star \star}$ & $0.579^{\star \star}$ & & & & & & & & \\
\hline 4. Aggression & $0.278^{\star *}$ & $0.565^{\star \star}$ & $0.607^{* \star}$ & & & & & & & \\
\hline 5. Anxious/Depressed & 0.099 & 0.120 & $0.226^{\star *}$ & $0.475^{\star \star}$ & & & & & & \\
\hline 6. Attention problems & $0.404^{* \star}$ & $0.362^{* *}$ & $0.317^{\star \star}$ & $0.583^{* \star}$ & $0.567^{\star \star}$ & & & & & \\
\hline 7. Destructive behavior & $0.248^{* \star}$ & $0.329^{* *}$ & $0.411^{\star \star}$ & $0.725^{\star \star}$ & $0.458^{\star \star}$ & $0.543^{* \star}$ & & & & \\
\hline 8. Social problems & $0.278^{* *}$ & $0.205^{* *}$ & $0.261^{* \star}$ & $0.476^{\star *}$ & $0.572^{* \star}$ & $0.730^{\star *}$ & $0.489^{* *}$ & & & \\
\hline 9. Somatic complaints & -0.004 & 0.053 & 0.021 & $0.269^{* \star}$ & $0.505^{* *}$ & $0.348^{* \star}$ & $0.249^{* *}$ & $0.326^{\star *}$ & & \\
\hline 10. Thought Problem & $0.272^{\star \star}$ & $0.272^{\star \star}$ & $0.312^{\star \star}$ & $0.467^{\star \star}$ & $0.371^{\star \star}$ & $0.496^{\star \star}$ & $0.485^{\star \star}$ & $0.433^{\star \star}$ & $0.272^{\star \star}$ & \\
\hline 11. Withdrawal & $0.154^{\star}$ & -0.051 & $0.155^{\star}$ & $0.322^{\star \star}$ & $0.637^{\star \star}$ & $0.470^{* \star}$ & $0.355^{\star \star}$ & $0.493^{\star *}$ & $0.376^{\star \star}$ & $0.492^{\star *}$ \\
\hline
\end{tabular}

${ }^{* *}: p<0.01 ;{ }^{*}: p<0.05$

(b)

(a)
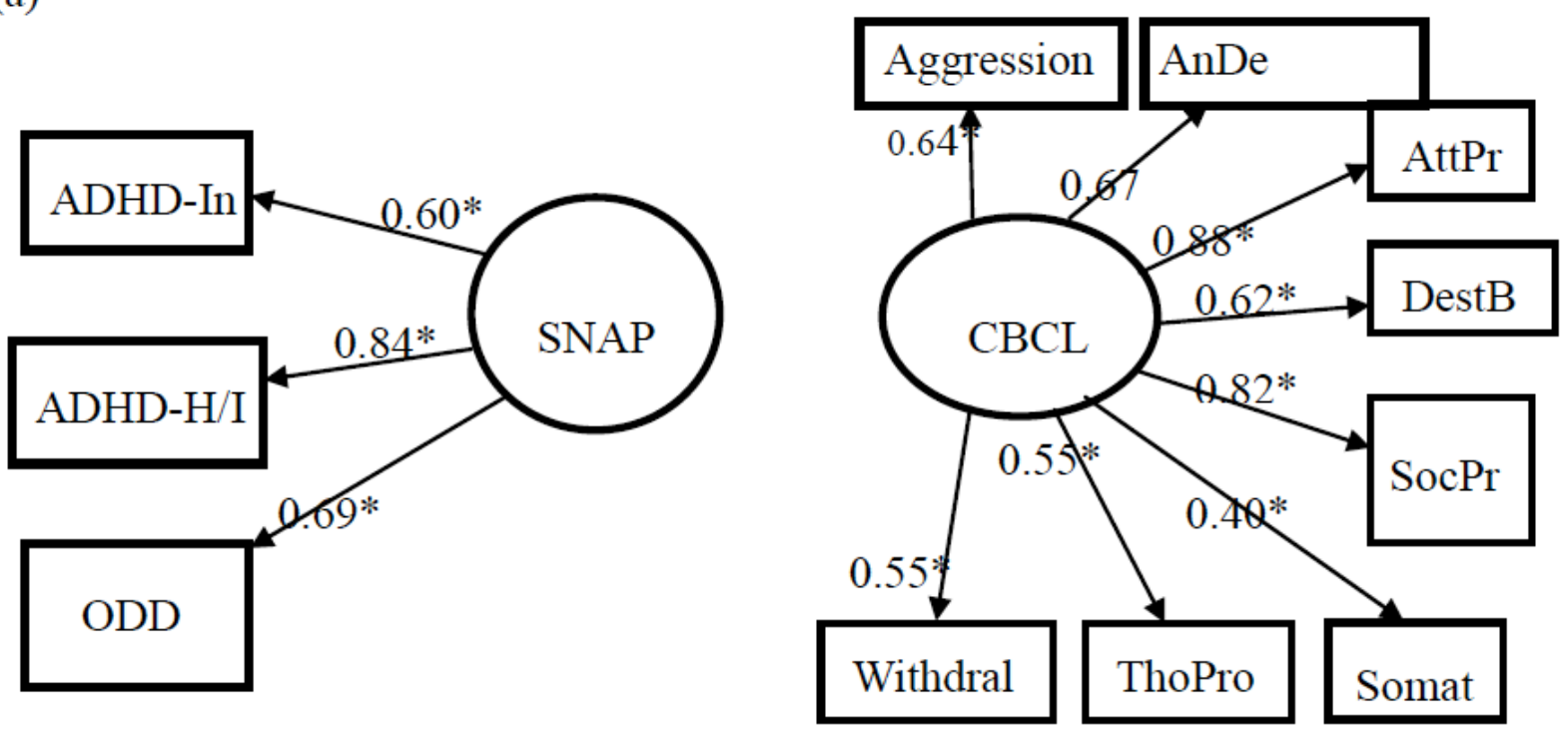

Figure 1: One-factor confirmatory factor analysis (CFA).

(a) A one-factor SEM model that represents SNAP as a single latent variable. Circle represents the latent variable, rectangles represent measured variables. ${ }^{*}=$ estimated parameters. All coefficients (presented in standardized form) are significant at the .05 level, ADHD-In: Inattention, ADHD-H/l: Hyperactivity/Impulsivity. X2 (1, N=183)=0.199, $\mathrm{p}=0.656, \mathrm{CFI}=1.00, \mathrm{NFI}=0.999$, $\mathrm{GFI}=0.999, \mathrm{TLI}=1.00, \mathrm{RMSEA}<0.001$.

(b) A one-factor SEM model that represents $\mathrm{CBCL}$ as a single latent variable. Circle represents the latent variable, rectangles represent measured variables. ${ }^{*}=$ estimated parameters. All coefficients (presented in standardized form) are significant at the .05 level. AnDe: Anxiety/Depression, AttPr: Attention Problems, DestB: Delinquent Behaviours, SocPr: Social Problems, Somat: Somatic Complaints, Thopro: Thought Problem. $\mathrm{X} 2(13, \mathrm{~N}=183)=11.062, \mathrm{p}=0.606, \mathrm{CFI}=1.00, \mathrm{NFI}=0.984, \mathrm{GFI}=0.985, \mathrm{TLI}=1.00$, RMSEA $<0.001$.

Figure 2 shows the SEM model positing the direct effect model of SNAP on CBCL. More specifically, the standardized direct effect of SNAP on CBCL is 0.57 . That is, when SNAP goes up by $1 \mathrm{SD}, \mathrm{CBCL}$ goes up by $0.57 \mathrm{SD}$. The SNAP accounted for $32 \%$ of the variance in the CBCL. This SEM model provides a very good fit for the data $\left(x^{2}(31)=31.95, p=0.234\right.$, $\mathrm{CFI}=0.995, \mathrm{NFI}=0.969, \mathrm{GFI}=0.968, \mathrm{TLI}=0.990$, RMSEA = 0.032). The corresponding standardized total, direct, and indirect effects of SNAP and CBCL were shown in Table 3. Especially, the standardized total (direct and indirect) effect of SNAP on Aggression 


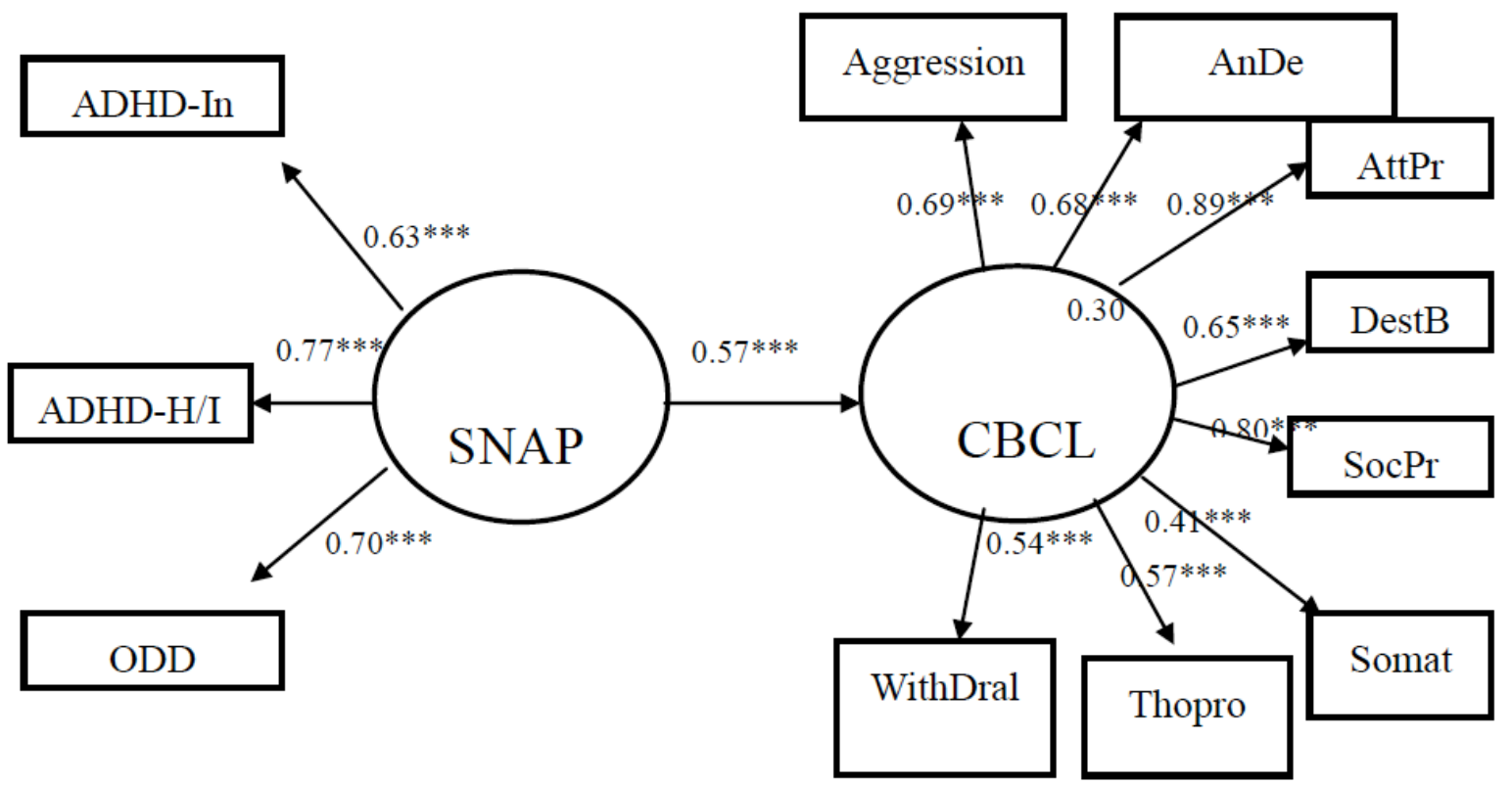

Figure 2: Basic model depicted the direct relationship between SNAP and CBCL. Circles represent latent variables, rectangles represent measured variables. ADHD-In: Inattention, ADHD-H/I: Hyperactivity/Impulsivity, AnDe: Anxiety/Depression, AttPr: Attention Problems, DestB: Delinquent Behaviours, SocPr: Social Problems, Somat: Somatic Complaints, Thopro: Thought Problem. ${ }^{* \star *}: p<0.001 . \mathrm{X} 2(31, \mathrm{~N}=183)=43.849, \mathrm{p}=.063, \mathrm{CFI}=0.987, \mathrm{NFI}=0.957, \mathrm{GFI}=0.957, \mathrm{TLI}=0.977, \mathrm{RMSEA}=0.048$.

Table 3: The Standardized Total, Direct, and Indirect Effects of SNAP and CBCL

\begin{tabular}{|c|c|c|c|c|c|c|}
\hline & \multicolumn{2}{|c|}{ Total Effects } & \multicolumn{2}{c|}{ Direct Effects } & \multicolumn{2}{c|}{ Indirect Effects } \\
\hline & SNAP & CBCL & SNAP & CBCL & SNAP & 0.00 \\
\hline CBCL & 0.55 & 0.00 & 0.57 & 0.00 & 0.00 \\
\hline Somat & 0.23 & 0.41 & 0.00 & 0.00 & 0.45 \\
\hline SocP & 0.45 & 0.80 & 0.00 & 0.00 & 0.00 \\
\hline Thopro & 0.33 & 0.58 & 0.00 & 0.54 & 0.31 & 0.00 \\
\hline WithDral & 0.31 & 0.54 & 0.00 & 0.69 & 0.39 & 0.00 \\
\hline Aggression & 0.39 & 0.69 & 0.00 & 0.68 & 0.38 & 0.00 \\
\hline AnDe & 0.38 & 0.68 & 0.00 & 0.89 & 0.50 & 0.00 \\
\hline AttPr & 0.50 & 0.89 & 0.00 & 0.65 & 0.37 & 0.00 \\
\hline DestB & 0.37 & 0.65 & 0.70 & 0.00 & 0.00 & 0.00 \\
\hline ODD & 0.70 & 0.00 & 0.77 & 0.00 & 0.00 \\
\hline ADHD-H/l & 0.77 & 0.00 & 0.63 & 0.00 & 0.00 \\
\hline ADHD-In & 0.63 & 0.00 & 0.00 & 0.00 \\
\hline
\end{tabular}

ADHD-In: Inattention; ADHD-H/l: Hyperactivity/Impulsivity; ODD: Oppositional Defiant Disorder; CBCL: child behavior checklist; AnDe: Anxiety/Depression; AttPr Attention Problems; DestB: Delinquent Behaviours; SocPr: Social Problems; Somat: Somatic Complaints; Thopro: Thought Problem.

is 0.39. That is, due to both direct (unmediated) and indirect (mediated) effects of SNAP on Aggression, when SNAP goes up by 1 SD, Aggression goes up by 0.39 SD.

Figure 3 depicted the direct relationship between ODD and CBCL. The standardized total (direct and indirect) effect of ODD on CBCL is 0.34 . That is, due to both direct (unmediated) and indirect (mediated) effects of ODD on CBCL, when ODD goes up by 1 standard deviation, CBCL goes up by 0.34 SD. Moreover, as shown in Table 4, the standardized total (direct and indirect) effect of ODD on Aggression is .21. That is, when ODD goes up by $1 \mathrm{SD}$, Aggression goes up by $0.21 \mathrm{SD}$. ODD accounted for $12 \%$ of the variance in the CBCL. This model also provided a very good fit for the data, as suggested by the non-significant chi-square and good indices of fit $\left(x^{2}(30)=34.116, p=0.163\right.$, 


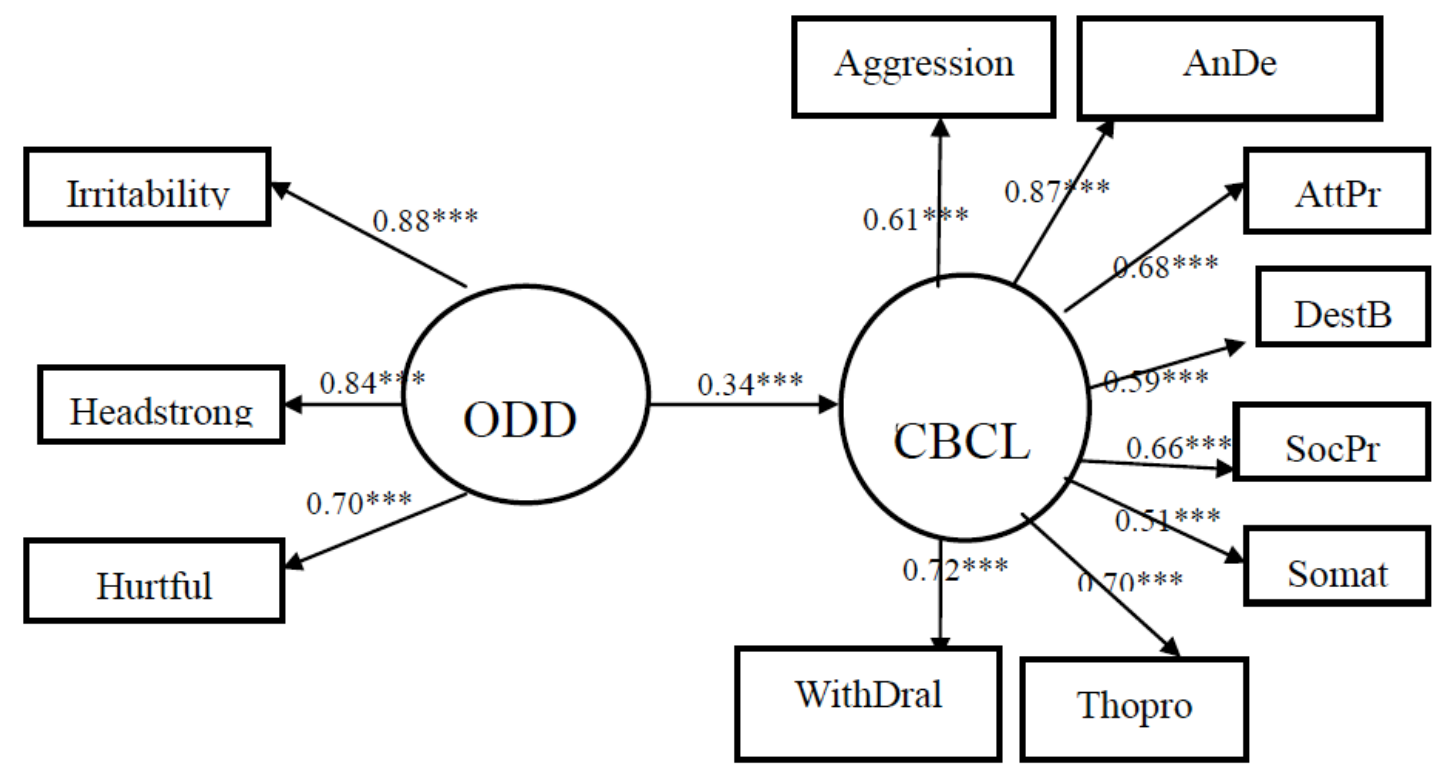

Figure 3: Basic model depicted the direct relationship between ODD and CBCL. The Circles represent unobserved latent variables. Rectangles represent observed measured variables. Values are standardized path coefficients. The squared multiple correlation (R2) value for the dependent variable appears above its circle or rectangle. ADHD-In: Inattention, ADHD-Hi: Hyperactivity, AnDe: Anxiety/Depression, AttPr: Attention Problems, DestB: Delinquent Behaviours, SocPr: Social Problems, Somat: Somatic Complaints, Thopro: Thought Problem. ${ }^{* *} ; p<0.001$.

Table 4: The Standardized Total, Direct, and Indirect Effects of ODD and CBCL

\begin{tabular}{|c|c|c|c|c|c|c|}
\hline & \multicolumn{2}{|c|}{ Total Effects } & \multicolumn{2}{c|}{ Direct Effects } & \multicolumn{2}{c|}{ Indirect Effects } \\
\hline & ODD & CBCL & ODD & CBCL & ODD & 0.00 \\
\hline \hline CBCL & 0.34 & 0.00 & 0.34 & 0.00 & 0.23 & 0.00 \\
\hline SocP & 0.23 & 0.66 & 0.00 & 0.66 & 0.18 & 0.00 \\
\hline Somat & 0.18 & 0.51 & 0.00 & 0.51 & 0.24 & 0.00 \\
\hline Thopro & 0.24 & 0.70 & 0.00 & 0.72 & 0.21 & 0.00 \\
\hline WithDral & 0.25 & 0.72 & 0.00 & 0.61 & 0.30 & 0.00 \\
\hline Aggression & 0.21 & 0.61 & 0.00 & 0.87 & 0.23 & 0.00 \\
\hline AnDe & 0.30 & 0.87 & 0.00 & 0.68 & 0.20 & 0.00 \\
\hline AttPr & 0.23 & 0.68 & 0.00 & 0.00 & 0.00 & 0.00 \\
\hline DestB & 0.20 & 0.59 & 0.00 & 0.00 & 0.00 & 0.00 \\
\hline Hurtful & 0.70 & 0.00 & 0.00 & 0.00 & 0.00 \\
\hline Headstrong & 0.84 & 0.00 & 0.00 & 0.88 & 0.00 & \\
\hline Irritability & 0.88 & 0.00 & 0.00 \\
\hline
\end{tabular}

ODD: Oppositional Defiant Disorder, CBCL: child behavior checklist, AnDe: Anxiety/Depression, AttPr: Attention Problems, DestB: Delinquent Behaviours, SocPr: Social Problems, Somat: Somatic Complaints, Thopro: Thought Problem.

$\mathrm{CFI}=0.993, \mathrm{NFI}=0.968, \mathrm{GFI}=0.967, \mathrm{TLI}=0.986$, RMSEA $=0.038$ ). The corresponding standardized total, direct, and indirect effects of ODD and CBCL were shown in Table 4.

\section{DISCUSSION}

This study aims to find the latent relationship between $A G G$ in $C B C L$ and $A D H D$ and ODD symptom measure by SNAP and, also to explore whether Aggression in CBCL correlated with ODD in SNAP by SEM analysis. This study indicates it is good to fit on basic factor analysis between ADHD and ODD symptom measured by SNAP to various behavior symptom measured by CBCL. There is significant interactive association between symptom of $A D H D$, ODD by SNAP and behavior symptom by CBCL; The ADHD and ODD by SNAP accounted for $55 \%$ of the 
variance in the behavior symptom in the CBCL and the ODD accounted for $33 \%$ of the variance behavior symptom in the CBCL.

This pathway analysis result indicates following 2 kind of complexity of transactions: 1, for AGG to ODD pathway: $A G G$ is more highly correlated with $O D D$ (0.607) than other destructive behaviour (0.411). 2, for AGG to ADHD pathway: Aggression in child is joined to ADHD symptom more in hyperactivity/impulsivity (ADHD-HI) symptom than ADHD-I subtype symptom by zero-order correlations. In summary, the presence of AGG on children implies the association with symptom severity of ADHD-I, ADHD-H/l, and ODD symptom. As expected, the clinical predictor of symptom severity of ADHD's ODD is a child also noticed to have aggressive behavior. This finding is reassuring the complexity of transactions between external vulnerable aggression and biologic risks of ADHD's ODD. Thus, following recent researcher suggesting children psychiatrist should save more limited power to children with visible symptom or biologic marker [29], we can regard ADHD's ODD plus aggressive symptom as having heavy genetic loading or aggression as visible marker to increase early awareness of the symptom severity of ADHD's ODD. If we follow the previous research from Pittsburg University demonstrating a child with ADHD + ODD + Conduct Disorder(CD) + Callous-Unemotional Traits is risky development on forming a psychosocial maladjustment disorder or disruptive behavior disorder [30], it might be too late to earlier recognize or treat the risk youth during clinical practice. If we imply such cross sectional pathway result recognizing aggression behavior among children with ADHD's ODD as early warning sign, more youth delinquency can be prevented earlier.

From present zero-order correlations result, we found ODD symptom from SNAP scale is severe enough to correlate significantly with 7 including internalizing and externalizing symptom of CBCL, e.g., aggressive Behaviours, Attention Problems, Anxiety/Depression, Social Problems, Delinquent Behaviours, Other problem, and Withdrawal except Somatic Complaints although Biederman et al. indicating deficient emotional self-regulation (DESR) among ADHD is significant associated with 3 behavior symptom of $\mathrm{CBCL}$ including aggressive, anxiety/depression, and inattentive symptom [4]. This result implies that children with ADHD's ODD symptom clinically shares similar interactive pathway which was expressed by emotional characteristic symptom as symptom of ADHD children with DESR.
Carlson et al. hypothesize ODD and depression share similar pathologic developmental pathway [3133]. This study result is in line with theirs also suggests ODD symptom by SNAP is closely correlated to symptom of Aggression, anxiety/depression agree measured by CBCL. Therefore we agree that the children with irritable ODD symptom would grow up as a depressive adult [34] also agree ODD is key pathologic risk for children to develop conduct disorder [18].

Worthy to mention is this study result also found the pathway that a child with ODD was noticed to develop an aggressive behavior is through indirect effect shown in Table 3. Our finding is in line with our hypothesis taking aggression on child as expression of inconsistent parenting and prior research indicating that most of the aggravating effects of ODD were from external adverse or dysfunctional family environment [35]. If children with both ADHD and ODD cannot be cared well, fearful potential risk of ADHD like criminal behavior [36] and possible precursor of bipolar disorder [37] might be noticed as they grow up. Therefore, the adequate treatment for those children with ADHD's ODD must be emphasized with more combination therapy including psycho-pharmacotherapy and parenting program to enhance the treatment effectiveness.

This study has the following limitations. First, the present study is limited by its cross-sectional and SEM design, which may not necessarily represent the longitudinal relationships among ADHD, ODD, Aggression. Also the fact that most of the scale is provided by a main caregiver, mainly mothers and teachers may lead to a sampling bias. Despite these limitations, this study with a sample of 231 from within the same ethnic group, clearly demonstrates an interactive relationship between ADHD, ODD, and Aggression.

\section{CONCLUSION}

This study use SEM to analyze the latent relationship among ADHD, ODD, Aggression. We suggest child psychiatrist regard combination of ADHD + ODD + Aggression as early marker of emotional dysregulation for children with ADHD because ODD plays aggravating role on ADHD's hyperactivity/impulsivity symptom and ODD and share a pathway of developing depression and Aggression. Aggression seen in child is joined warning sign for children with ADHD's ODD. In summary, we can regard ADHD's ODD plus aggressive 
symptom as having heavy genetic loading and or predictor of disruptive behavior disorder.

\section{ACKNOWLEDGEMENT}

None.

\section{STATEMENT OF INTEREST}

None of the authors have any conflicts of interest with regards to this research.

\section{REFERENCES}

[1] Nagin D, Tremblay RE. Trajectories of boys' physical aggression, opposition, and hyperactivity on the path to physically violent and nonviolent juvenile delinquency. Child Dev 1999; 70(5): 1181-96. http://dx.doi.org/10.1111/1467-8624.00086

[2] Jester JM, Nigg JT, Adams K, Fitzgerald HE, Puttler LI, Wong $\mathrm{MM}$, et al. Inattention/hyperactivity and aggression from early childhood to adolescence: heterogeneity of trajectories and differential influence of family environment characteristics. Development and psychopathology 2005; 17(1): 99-125. http://dx.doi.org/10.1017/S0954579405050066

Pederson CA, Fite PJ. The Impact of Parenting on the Associations Between Child Aggression Subtypes and Oppositional Defiant Disorder Symptoms. Child psychiatry and human development 2014

http://dx.doi.org/10.1007/s10578-014-0441-y

[4] Biederman J, Spencer T, Lomedico A, Day H, Petty CR, Faraone SV. Deficient emotional self-regulation and pediatric attention deficit hyperactivity disorder: a family risk analysis. Psychol Med 2012; 42(3): 639-46.

http://dx.doi.org/10.1017/S0033291711001644

[5] Barkley RA. Deficient Emotional Self-Regulation: A Core Component of Attention-Deficit/Hyperactivity Disorder. Journal of ADHD and Related Disorders 2010; 1(2): 5-37.

[6] Becker SP, Luebbe AM, Fite PJ, Greening L, Stoppelbein L. Oppositional defiant disorder symptoms in relation to psychopathic traits and aggression among psychiatrically hospitalized children: ADHD symptoms as a potential moderator. Aggressive behavior 2013; 39(3): 201-11. http://dx.doi.org/10.1002/ab.21471

Aebi M, Plattner B, Metzke CW, Bessler C, Steinhausen HC. Parent- and self-reported dimensions of oppositionality in youth: construct validity, concurrent validity, and the prediction of criminal outcomes in adulthood. J Child Psychol Psychiatry 2013; 54(9): 941-9.

http://dx.doi.org/10.1111/jcpp.12039

[8] Stringaris A, Goodman R. Three dimensions of oppositionality in youth. J Child Psychol Psychiatry 2009; 50(3): 216-23.

http://dx.doi.org/10.1111/j.1469-7610.2008.01989.x

[9] Pardini DA, Fite PJ. Symptoms of conduct disorder, oppositional defiant disorder, attention-deficit/hyperactivity disorder, and callous-unemotional traits as unique predictors of psychosocial maladjustment in boys: advancing an evidence base for DSM-V. J Am Acad Child Adolesc Psychiatry 2010; 49(11): 1134-44.

[10] Kim HW, Cho SC, Kim BN, Kim JW, Shin MS, Yeo JY. Does oppositional defiant disorder have temperament and psychopathological profiles independent of attention deficit/hyperactivity disorder? Compr Psychiatry 2010; 51(4): 412-8.
[11]

Masi G, Muratori P, Manfredi A, Lenzi F, Polidori L, Ruglion $\mathrm{L}$, et al. Response to treatments in youth with disruptive behavior disorders. Compr Psychiatry 2013. http://dx.doi.org/10.1016/i.comppsych.2013.04.007

[12] Ercan ES, Kandulu R, Uslu E, Ardic UA, Yazici KU, Basay $\mathrm{BK}$, et al. Prevalence and diagnostic stability of ADHD and ODD in Turkish children: a 4-year longitudinal study. Child and adolescent psychiatry and mental health 2013; 7(1): 30 . http://dx.doi.org/10.1186/1753-2000-7-30

[13] Coghill D. Editorial: Do clinical services need to take conduct disorder more seriously? J Child Psychol Psychiatry 2013; 54(9): 921-3. http://dx.doi.org/10.1111/jcpp.12135

[14] Poulton AS. Time to redefine the diagnosis of oppositional defiant disorder. J Paediatr Child Health 2011; 47(6): 332-4 http://dx.doi.org/10.1111/j.1440-1754.2010.01736.x

[15] Kuhne M, Schachar R, Tannock R. Impact of comorbid oppositional or conduct problems on attention-deficit hyperactivity disorder. J Am Acad Child Adolesc Psychiatry 1997; 36(12): 1715-25. http://dx.doi.org/10.1097/00004583-199712000-00020

[16] Kadesjo C, Hagglof B, Kadesjo B, Gillberg C. Attentiondeficit-hyperactivity disorder with and without oppositional defiant disorder in 3- to 7-year-old children. Dev Med Child Neurol 2003; 45(10): 693-9. http://dx.doi.org/10.1017/S0012162203001282

[17] Elia J, Ambrosini P, Berrettini W. ADHD characteristics: I. Concurrent co-morbidity patterns in children \& adolescents. Child and adolescent psychiatry and mental health 2008; 2(1): 15.

http://dx.doi.org/10.1186/1753-2000-2-15

[18] Burke JD, Hipwell AE, Loeber R. Dimensions of oppositional defiant disorder as predictors of depression and conduct disorder in preadolescent girls. J Am Acad Child Adolesc Psychiatry 2010; 49(5): 484-92.

[19] Burke JD, Loeber R. The Effectiveness of the Stop Now and Plan (SNAP) Program for Boys at Risk for Violence and Delinquency. Prevention science : the official journal of the Society for Prevention Research 2014.

[20] Violato C, Hecker KG. How to use structural equation modeling in medical education research: a brief guide Teaching and learning in medicine 2007; 19(4): 362-71. http://dx.doi.org/10.1080/10401330701542685

[21] Swanson JM, Kraemer HC, Hinshaw SP, Arnold LE, Conners $\mathrm{CK}$, Abikoff $\mathrm{HB}$, et al. Clinical relevance of the primary findings of the MTA: success rates based on severity of ADHD and ODD symptoms at the end of treatment. J Am Acad Child Adolesc Psychiatry 2001; 40(2): 168-79. http://dx.doi.org/10.1097/00004583-200102000-00011

[22] Liu YC, Liu SK, Shang CY, Lin CH, Tu C, Gau SS. Norm of the Chinese Version of the Chinese version of the Swanson, Nolan, and Pelham, version IV scale for ADHD. Taiwanese $J$ psychiatry 2006; 20(4): 290-304.

[23] Huang HL, Chuang SF, Wang YC, editors. Developing the multiaxial behavioral assessment of children in Taiwan. In Psychological Assessment in Chinese- Speaking Society [in Chinese]. Taipei, Taiwan: Chinese Assessment Association; 2004.

[24] Yang HJ, Soong WT, Chiang CN, Chen WJ. Competence and behavioral/emotional problems among Taiwanese adolescents as reported by parents and teachers. J Am Acad Child Adolesc Psychiatry 2000; 39(2): 232-9. http://dx.doi.org/10.1097/00004583-200002000-00024

[25] Arbuckle JL. IBM SPSS Amos 21.0 User's Guide: AMOS Development Corporation.; 2012.

[26] Bentler PM, Bonett DG. Significance tests and goodness of fit in the analysis of covariance structures. Psychol Bull 1980; 88: 588-606.

http://dx.doi.org/10.1037/0033-2909.88.3.588 
[27] Browne MW, Cudeck R. Testing structural equation models. London: Sage Ltd.; 1993.

[28] Hooper D, Coughlan J, Mullen MR. Structural Equation Modelling: Guidelines for Determining Model Fit. . The Electronic Journal of Business Research Methods 2008; 6: 53-60.

[29] What lies beneath. Nature 2014; 507(7492): 273. http://dx.doi.org/10.1038/507273a

[30] Kolko DJ, Pardini DA. ODD dimensions, ADHD, and callousunemotional traits as predictors of treatment response in children with disruptive behavior disorders. J Abnorm Psychol 2010; 119(4): 713-25. http://dx.doi.org/10.1037/a0020910

[31] Carlson GA, Cantwell DP. Unmasking masked depression in children and adolescents. The American journal of psychiatry 1980; 137(4): 445-9.

[32] Ezpeleta L, Domenech JM, Angold A. A comparison of pure and comorbid CD/ODD and depression. Journal of Child Psychology and Psychiatry and Allied Disciplines 2006; 47(7): 704-12.

http://dx.doi.org/10.1111/j.1469-7610.2005.01558.x

[33] Vance A, Sanders M, Arduca Y. Dysthymic disorder contributes to oppositional defiant behaviour in children with Attention Deficit Hyperactivity Disorder, combined type
(ADHD-CT). Journal of affective disorders 2005; 86(2-3): 329-33.

http://dx.doi.org/10.1016/.j.jad.2005.03.007

[34] Burke JD, Loeber R, Lahey BB, Rathouz PJ. Developmental transitions among affective and behavioral disorders in adolescent boys. Journal of Child Psychology and Psychiatry and Allied Disciplines 2005; 46(11): 1200-10.

http://dx.doi.org/10.1111/j.1469-7610.2005.00422.x

[35] Greene RW, Biederman J, Zerwas S, Monuteaux MC, Goring JC, Faraone SV. Psychiatric comorbidity, family dysfunction, and social impairment in referred youth with oppositional defiant disorder. Am J Psychiatry 2002; 159(7): 1214-24. http://dx.doi.org/10.1176/appi.ajp.159.7.1214

[36] Gudjonsson GH, Sigurdsson JF, Adalsteinsson TF, Young S. The relationship between ADHD symptoms, mood instability, and self-reported offending. Journal of attention disorders 2013; 17(4): 339-46. http://dx.doi.org/10.1177/1087054711429791

[37] Biederman J, Petty CR, Byrne D, Wong P, Wozniak J, Faraone SV. Risk for switch from unipolar to bipolar disorder in youth with ADHD: a long term prospective controlled study. J Affect Disord 2009; 119(1-3): 16-21. http://dx.doi.org/10.1016/.j.jad.2009.02.024

(C) 2014 Tzang et al.; Licensee Lifescience Global.

This is an open access article licensed under the terms of the Creative Commons Attribution Non-Commercial License (http://creativecommons.org/licenses/by-nc/3.0/) which permits unrestricted, non-commercial use, distribution and reproduction in any medium, provided the work is properly cited. 